\title{
Modelo Conceptual integrativo de Destination Branding: teste empírico no Porto e Norte de Portugal
}

\author{
Pedro Costa Carvalho* \\ Ana Maria Pinto Lima Vieira Brites Kankura Salazar** \\ Paulo Matos Graça Ramos****
}

Universidade Fernando Pessoa (Portugal)

\begin{abstract}
Resumo: O presente estudo tem como objetivo desenvolver e testar um novo modelo conceptual de branding de destinos turísticos, incluindo e integrando os conceitos de identidade de marca (associações da marca), da imagem da marca, da qualidade percebida, da satisfação e da lealdade turística. Este estudo levanta hipóteses de relação entre estes constructos. Este artigo pretende contribuir para a conceptualização do destination branding que é identificado como um conceito crítico para a competitividade dos destinos turísticos.
\end{abstract}

Palavras -Chave: Identidade da marca, Imagem da marca, Qualidade percebida, Satisfação turística, Lealdade turística.

Conceptual integrative model of Destination Branding: empirical test in Porto and North of Portugal

Abstract: The current study aims to develop and test a new conceptual model for destination branding, including and integrating the concepts of brand identity (brand associations), brand image, perceived quality, satisfation and loyalty. This study hypothesizes relationships among this constructs. This article aims to contribute to the conceptualization of destination branding that is identified as critical concept to the competitiveness of tourist destinations.

Keywords: Brand identity, Brand image, Perceived quality, Tourist satisfation, Tourist loyalty.

\section{Introdução}

A imagem de destinos turísticos (doravante designada pela sigla IDT), numa perspetiva de marketing, está fundamentalmente ligada ao comportamento do consumidor. Como refere Buhalis (2000) os destinos turísticos competem principalmente através da IDT, desde que a imagem que os turistas têm dos destinos antes da visita seja um fator determinante na decisão de compra do produto "destino turístico". Cerca de $70 \%$ dos fluxos internacionais do turismo são concentrados em apenas 10 países, assistindo-se a uma forte competitividade entre destinos turísticos (Morgan et al., 2002). Ramos et al. (2000) salientam que o setor do turismo em Portugal deve concentrar a sua vantagem competitiva na genuinidade do seu produto com uma herança cultural específica, que potencia a diferenciação. Pike (2009) identificou vários gaps para investigação e refere a insuficiência de pesquisa na avaliação dos esforços de marketing dos destinos turísticos por forma a melhorar o valor da marca. Cai (2002) considera que o núcleo do destination branding é a construção de uma imagem positiva dos destinos turísticos que identifica e diferencia o destino de outros através de um mix de associações da identidade da marca, e Hudson e Ritchie (2009) salientam que o destination branding é uma abordagem emergente

\footnotetext{
* Doutorando em Ciências Empresariais (Ramo Marketing) na FCHS-UFP, Professor na ESTF-IESF; E-mail: 17563@ufp.edu.pt

** Doutora em Gestão, Professora na FCHS-UFP; E-mail: aks@ufp.edu.pt

**** Doutor em Ciências Empresariais, Professor na FCHS-UFP; E-mail: pramos@ufp.edu.pt
} 
e poderosa do marketing para os marketers contemporâneos. Neste âmbito, o presente estudo constitui uma proposta de um modelo de destination branding.

O objetivo deste estudo é o de compreender o processo de formação do destination branding, nomeadamente as suas dimensões e a sua inter-relação propondo um modelo de destination branding que seja um contributo para a avaliação e monitorização, do comportamento do turista e da performance dos destinos turísticos, através de uma perspetiva integrada.

\section{Revisão de Literatura}

\subsection{A evolução conceptual da imagem de destinos turísticos: da abordagem centrada no produto à abordagem centrada na marca - Destination Branding}

O conceito de IDT é um conceito complexo, mas verifica-se unanimidade na academia em caraterizar a IDT como uma construção mental desenvolvida pelo turista enquanto consumidor e uma impressão holística produzida pelo destino turístico (Echtner e Ritchie, 1991), que incluiu subjetividade na perceção (Bigné et al., 2001), e a relevância da IDT para a gestão de destinos turísticos tem permitido um grande foco na sua conceptualização (Pike, 2002). O conceito de "imagem" justificou e justifica, por isso, uma atenção considerável por parte de investigadores e dos profissionais da indústria do turismo. Será que a perceção holística da IDT, demasiado ligada aos atributos dos destinos turísticos, permite obter uma imagem completa do turista em relação a um destino turístico?

De acordo com Anholt (2003) os locais sempre foram marcas, tendo como objetivo o crescimento, como acontece com o turismo, e a procura de uma imagem positiva, ainda que só recentemente o marketing tenha sido considerado como importante. Este autor salienta no entanto que o branding dos locais é diferente do branding dos produtos, pois os locais (como os destinos turísticos) representam maior complexidade do que de produtos/serviços isolados. Conforme refere Pike (2009), a investigação relativa ao branding de destinos turísticos, ou seja, o estudo da imagem numa perspetiva da marca dos destinos turísticos, é recente. Os primeiros artigos publicados em jornais científicos, só surgiram em 1998, e a primeira conferência internacional dedicada ao tema teve lugar em Macau em 2005. Não é surpresa que esta abordagem de branding seja recente, pois o próprio conceito de marca teve pouca expressão na literatura de marketing até ao início da década de 1990 (Grönroos, 2004).

É defendido que a formação da IDT compreende três componentes principais, a cognitiva, a afetiva e a conativa ou comportamental (Gartner, 1993). De acordo com Martín e Bosque (2008) a componente cognitiva está relacionada com os atributos do destino turístico que pode ser funcional/tangível (ex: paisagem, atrações culturais), e psicológica/abstrata (ex: hospitalidade, clima). Por outro lado, a componente afetiva está relacionada com as emoções que um destino turístico é capaz de evocar (ex: prazer, excitação). De acordo com Gartner (1993) a imagem conativa prende-se com o comportamento do turista relativamente ao destino turístico visitado.

O sucesso do marketing de destinos turísticos depende de um efetivo posicionamento estratégico (Echtner e Ritchie, 1991), sendo defendido, por isso, a importância de se incluírem as marcas num processo adequado de planeamento e gestão de destinos turísticos apesar da complexidade que um elevado número de stakeholders representa. A American Marketing Association (doravante designada pela sigla AMA) (https://www.ama.org) define brand (marca) como um nome, um termo, design, símbolo, ou qualquer outra caraterística que identifica um produto ou serviço de uma empresa como distinto do produto ou serviço de outras empresas. A AMA define brand image (imagem da marca) como a perceção de uma marca na mente das pessoas, enquanto reflexo de espelho (embora talvez imprecisa) da personalidade da marca ou do produto, o que as pessoas acreditam sobre uma marca através dos seus pensamentos, sentimentos e expetativas (https://www.ama.org). Blain et al. (2005: 337) delimitaram o conceito de destination branding, integrando o resultado de estudos teóricos e empíricos. Estes autores definiram destination branding como o conjunto de actividades de marketing que:

1) suporta a criação de um nome, símbolo, logótipo, assinatura da marca ou outro gráfico que facilmente identifica e diferencia um destino;

2) transmite consistentemente a expetativa de uma experiência memorável de viagem que está unicamente associada com o destino;

3) serve para consolidar e reforçar a conexão emocional entre o visitante e o destino;

4) permite reduzir os custos de pesquisa sobre o consumidor e identifica riscos no mercado. 
Coletivamente, essas atividades servem para criar uma imagem de destino, que influencia positivamente o consumidor na escolha do destino turístico.

\subsection{Relação das associações da identidade da marca com a imagem da marca}

Para Aaker (1996) a identidade da marca oferece sentido, finalidade e significado à marca, sendo central para a visão estratégica da marca e incitadora das associações da marca e representa para a marca o seu "coração" e "espírito". De acordo com Aaker e Joachimsthaler (2007: 60) contrariamente à imagem de marca, que é recetora, a identidade de marca é aspiracional. Dito por outras palavras, a identidade das marcas turísticas dos territórios são a forma como os seus gestores das marcas pretendem que as mesmas sejam percebidas pelos turistas. De acordo com estes autores, a identidade da marca é um conjunto de associações da marca que implicam uma promessa por parte de uma determinada empresa/organização aos seus clientes, sendo a identidade que conduz todos os esforços de construção da marca. Existem associações da marca em 12 categorias enquadradas em torno de 4 perspetivas, a saber:

1) a marca como produto (alcance do produto, atributos do produto, qualidade/valor, experiência de utilização, clientes, país de origem);

2) a marca como organização (atributos organizativos, relação local/global);

3) a marca como pessoa (personalidade da marca, e relações cliente-marca),

4) a marca como símbolo (imagens visuais/metáforas e heranças ou tradições da marca).

Normalmente nenhuma marca possui associações nas 12 categorias, mas cada marca precisa de entre 6 a 12 dimensões para descrever adequadamente as aspirações da marca. A identidade da marca está estruturada em (a) identidade central, (b) identidade expandida, e (c) essência da marca. A identidade central é identificada como o elemento mais importante da identidade da marca, aquele que deve permitir a diferenciação no mercado, podendo incluir como elementos por exemplo: confiança, relacionamento emocional, inovação, e o valor por dinheiro. A identidade expandida inclui elementos concisos da marca, como por exemplo a criatividade para proteger a marca, a personalidade da marca, e os símbolos da marca. A essência da marca é o ícone da marca, com foco nas dimensões da identidade central que refletem a visão da marca, uma ideia que deve conquistar a alma da marca. A essência da marca deve forcar-se no que é a marca (benefícios funcionais) ou no que faz ao cliente (benefícios emocionais), e comunicar energicamente a identidade (Aaker e Joachimsthaler, 2007).

Keller (1993: 3-5) classifica as associações da marca em três categorias principais, a saber: (1) atributos, (2) benefícios e (3) atitudes.

1) os atributos são as caraterísticas de um produto ou serviço, o que o consumidor pensa que esse produto ou serviço é, ou que está envolvido na compra ou consumo.

2) os benefícios são o valor de um produto ou serviço associado aos atributos desse produto ou serviço, que representam o que o consumidor pensa que o produto ou serviço pode fazer por ele.

3) as atitudes são definidas como a avaliação global da marca, sendo importantes porque normalmente formam a base para o comportamento do consumidor (por exemplo, a escolha da marca), resultando a associação da atitude da "saliência" da marca, ou seja de associações integradas de atributos e de benefícios de produtos e serviços para o consumidor e do julgamento do consumidor em relação a essas associações.

Aaker (1996) defende que não deve haver uma fixação exclusiva da identidade da marca nos atributos do produto, justificando que uma marca é mais do que o produto, e que os atributos do produto não são a única base para a decisão do cliente, pois a marca inclui outras associações potencialmente relevantes, por exemplo a personalidade da marca, e as relações marca-cliente.

Tendo como suporte os argumentos que resultam da revisão da literatura, formula-se a seguinte hipótese:

$\mathrm{H}^{\text {1a: }}$ As associações da identidade da marca permitem explicar mais significativamente a imagem do destino turístico (abordagem centrada na marca), do que apenas os atributos do destino turístico (abordagem centrada no produto).

Aaker (1996) faz uma analogia da identidade de uma marca com a identidade de uma pessoa, sugerindo a reflexão para as seguintes questões importantes que uma pessoa levanta: Quais são os meus valores essenciais? O que pretendo? Como desejo ser percebido? Que traço de personalidade gostaria de projetar? 
Quais são os relacionamentos importantes na minha vida? De acordo com Aaker (1991) as marcas podem tornar-se símbolos de autoexpressão de uma pessoa. Assim, uma marca pode oferecer a possibilidade de a pessoa comunicar a sua autoimagem (por exemplo de responsável, ou competente) através do uso de marcas que estimulem o encontro entre a marca e o cliente. Konecnik e Gartner (2007) sugeriram que em estudos futuros se integrassem mais dimensões da imagem, separadas, destacando a personalidade da marca. Aaker (1997) define a personalidade da marca como o conjunto de caraterísticas humanas associadas à marca. Ekinci e Hosany (2006) tinham já sugerido que a personalidade da marca dos destinos turísticos pode ser usada como uma metáfora viável para a construção da marca dos destinos turísticos, para entender as perceções dos visitantes e para criar uma identidade única para os destinos turísticos. Nam et al. (2011) confirmaram a congruência entre a imagem dos turistas e a imagem dos turistas em relação ao destino turístico, ou seja a autoimagem.

Considerando que a referência à personalidade da marca sobressai notoriamente no contexto das associações da marca, formula-se, assim, a seguinte hipótese:

\section{$\mathrm{H}^{1 \mathrm{~b}}$ : A personalidade da marca é a associação da identidade da marca que mais contribui para a formação da imagem da marca do destino turístico Porto e Norte.}

\subsection{A relação entre as associações da marca e a atitude de lealdade}

Como refere Aaker (1991) sem as recordações da emoção que uma marca evoca, a marca não passaria de uma commodity ou seja de objeto útil ou de conveniência. Este autor salienta que uma marca com um conjunto de associações forte gera uma imagem de marca forte. Segundo Keller (1993), as associações da marca podem ser caraterizadas pela força da ligação ao nó da marca, o que depende da forma como a informação entra na memória do consumidor ou seja codificação (encoding) e também da forma como é mantida ou armazenada (storage) como imagem da marca. Para este autor, a congruência entre associações da marca determina a coesão da imagem da marca, e esta coesão pode determinar reações mais holísticas ou como um todo em relação à marca. Uma insuficiência de congruência entre as associações da marca leva a uma imagem da marca difusa, o que pressupõe que os consumidores estão confusos relativamente à marca, porque as associações não congruentes são menos fortes e assim menos favoráveis à marca, e porque se as associações não constituírem uma imagem da marca resultante da construção de um todo de associações serão mais facilmente afetadas pelas ações de competição do mercado. Quer isto dizer, que uma maior favorabilidade do consumidor em relação à marca, que uma maior força da marca na mente do consumidor, e que uma maior singularidade da marca em relação à concorrência potencia uma atitude mais favorável do turista em relação à marca de um destino turístico.

Formula-se, assim, a seguinte hipótese:

$\mathrm{H}^{1 \mathrm{c}}$ : Quanto mais fortes e congruentes forem as associações da marca do destino turístico maior será o impacto na atitude de lealdade em relação à marca do destino turístico.

\subsection{A relação entre a imagem da marca e a qualidade percebida na experiência turística atual}

Para Grönroos (2004) uma marca não pode ser criada nem existir sem a presença do cliente, considerando que a marca como conceito é sempre uma imagem. Este autor define a marca baseada na noção de relacionamento do cliente, como o desenvolvimento continuado de relacionamentos com a marca nos quais o cliente forma uma imagem diferenciadora de um bem físico, um serviço, com base em todos os tipos de contactos com a marca a que aquele cliente está exposto.

Žabkar et al. (2010) estudaram a qualidade percebida e a satisfação em destinos turísticos como antecedentes da intenção comportamental, admitindo como limitação, a necessidade de estudo da influência e interação de outros fatores, sugerindo para o efeito a imagem. Esta conclusão pode entender-se ao abrigo do defendido por Aaker (1991), ao referir que maioria dos benefícios funcionais incorpora emoções o que se prende com associações da marca.

Grönroos (2004) salienta o papel da imagem como filtro dos efeitos da comunicação e da recomendação, na medida em que uma imagem positiva confere maior recetividade em relação a informação e recomendação sobre uma determinada marca, assim como uma imagem negativa tem um efeito semelhante em sentido contrário. Este autor refere que a imagem tem a função de filtro na perceção da qualidade técnica (resultado) e da qualidade funcional (processo). Se a imagem for boa, protege a performance na prestação de serviços, podendo gerar tolerância do cliente perante problemas menores 
ou até maiores (ocasionais), desde que não sejam recorrentes, no contexto dos processos de serviço. Contrariamente, se a imagem antes dos processos for má, os clientes reagem com maior insatisfação perante os mesmos problemas na performance de prestação de serviços. Uma imagem neutra ou de ausência de familiaridade não prejudica mas também não protege a marca.

Formula-se, assim, a seguinte hipótese:

\section{$\mathrm{H}^{1 \mathrm{~d}}$ : Existe uma relação significativa entre a imagem da marca do destino turístico e a qualidade percebida na experiência turística atual.}

\subsection{A relação entre a imagem da marca e a satisfação}

De acordo com Oliver (1980) a satisfação é um conceito pós consumo. Este autor desenvolveu o modelo da desconfirmação das expectativas, verificando-se uma desconfirmação positiva quando a perceção do cliente for superior às expetativas, e uma desconfirmação negativa quando a perceção do cliente for inferior às expetativas, pois nesse caso verifica-se uma diminuição da satisfação, existindo satisfação quando o resultado da experiência corresponde pelo menos ao que o cliente esperava antes da mesma. Para Bigné et al. (2001) a satisfação de um turista relativamente à sua experiência num destino turístico é considerada uma dimensão de essencial importância para a avaliação da IDT. Estes autores confirmam uma relação direta e positiva entre a IDT e a satisfação.

Formula-se, assim, a seguinte hipótese:

\section{$H^{1 \mathrm{e}}$ : Existe uma relação significativa entre a imagem da marca do destino e a satisfação.}

\subsection{A relação entre a imagem da marca e a lealdade}

Aaker (1991) considera a lealdade a dimensão central do valor da marca, pois é de esperar que clientes leais gerem um lucro previsível, uma vez que manter clientes representa um custo muito inferior ao custo de conquistar novos clientes, porque a fidelização cria uma barreira à concorrência e porque clientes fiéis podem recomendar a marca e assim aumentar o número de clientes. Para este autor as associações da marca são a base para a imagem da marca mas também são a base para as decisões de compra, pois uma associação da marca pode representar um importante suporte para a diferenciação da marca.

Segundo Oliver (1999) a lealdade afetiva verifica-se quando o consumidor se revela leal através da maior profundidade de compromisso (commitment), a lealdade conativa verifica-se quando o consumidor tem intenção de voltar a comprar a marca, mas esta intenção pode não resultar no ato de compra, e a lealdade atitudinal representa o compromisso de voltar a comprar a marca. De acordo com Bandyopadhyay e Martell (2007) a lealdade pode considerar-se sob duas perspetivas: a lealdade comportamental e a lealdade atitudinal. A lealdade comportamental refere-se à frequência de repetição da compra, enquanto a lealdade atitudinal refere-se ao compromisso psicológico que um cliente faz no ato da compra, como a intenção de comprar, a intenção de voltar a comprar e a intenção de recomendar uma marca a outras pessoas. Para Nam et al. (2011) a abordagem atitudinal é mais apropriada para estudar a lealdade no turismo, porque os turistas podem ser leais a um destino mesmo ainda que não o visitem.

Keller (2003) dá foco à atitude de ligação do consumidor à marca, definindo-a como uma atitude positiva, pois ainda que o cliente não escolha sempre a marca, esta estará entre as suas principais opções. Isto é, a lealdade integra-se num conceito mais amplo, o dos "relacionamentos". Martín e Bosque (2008) defendem que a lealdade não é somente julgada pela satisfação, mas também por uma imagem pré-concebida que independentemente do nível de satisfação pode representar intenções futuras de voltar e de recomendar, e que o efeito inverso também acontece. Isto é, a perceção de satisfação não garante necessariamente uma intenção futura favorável.

No estudo de Yoo e Donthu (2001), a lealdade à marca é estudada como a tendência para o cliente ser leal, o que é expresso através da intenção de comprar a marca como primeira escolha. Confirma-se a existência de uma relação positiva e direta entre a imagem e as atitudes de lealdade dos turistas (Bigné et al., 2001).

Formula-se, assim, a seguinte hipótese:

$H^{1:}$ Existe uma relação significativa entre a imagem da marca do destino turístico e (a) o comportamento de lealdade em relação à marca do destino turístico, e (b) a atitude de lealdade em relação à marca do destino turístico. 


\subsection{A relação da qualidade com a satisfação e com a lealdade}

Grönroos (2004) refere que medir expetativas na avaliação da qualidade percebida do cliente representam um problema de medição e de validade, pelos seguintes motivos, a saber: (a) se as expetativas forem medidas após ou durante a experiência do serviço, o que é medido não é realmente a expetativa mas algo que sofreu o viés da experiência, ou seja uma distorção no julgamento; (b) também não sugere fazer sentido medir expetativas antes da experiência porque as expetativas que os clientes têm poderão depois não corresponder com a experiência específica de consumo; (c) as expetativas são inerentes a perceções anteriores e as experiências são perceções da realidade. Žabkar et al. (2010) referem-se à dificuldade em delimitar a qualidade percebida e a satisfação devido ao seu alto nível de correlação.

Segundo Grönroos (2004) o valor final para os clientes surge no consumo ou utilização do serviço, e se o cliente não ficar satisfeito com a experiência, os esforços de produção prévia terão sido em vão. Žabkar et al. (2010) comprovaram que a qualidade percebida da experiência turística permite conhecer os aspetos cognitivos do comportamento, enquanto a satisfação do turista permite conhecer, numa avaliação global, tanto os aspetos cognitivos como emocionais do comportamento, o que sugere que a qualidade tenha um impacto positivo na satisfação, justificando uma parte da perceção cognitiva.

Para Grönroos (2004), os serviços requerem uma abordagem de gestão do relacionamento de clientes, porque os serviços são iminentemente relacionais. Entende-se como um processo cada momento de contacto entre o prestador de serviço e o cliente ou vice-versa, ou seja um simples contacto telefónico de um cliente para um restaurante é um processo. Uma interação entre "cliente e prestador de serviços" significa um encontro que pode conduzir a um relacionamento, se os encontros se repetirem de forma continuada. No entanto, o autor explica que o facto de haver um relacionamento percebido (a repetição da compra é um bom indicador) não significa que os clientes sejam fiéis. Para que um relacionamento efetivo aconteça, é necessário que o cliente o perceba que existe interesse entre si e o fornecedor do serviço o que significa, em certa medida, um compromisso.

Formulam-se, assim, as seguintes hipóteses:

$H^{2 a}$ : Existe um impacto significativo da (a) qualidade percebida na satisfação, (b) do valor percebido e da qualidade percebida na satisfação.

$H^{2 b}$ : Existe uma relação significativa entre a qualidade percebida e a atitude de lealdade à marca do destino turístico.

\subsection{A relação da satisfação com a lealdade}

De acordo com Oliver (1999) a satisfação consiste na resposta do consumidor relativamente à avaliação do consumo de um produto ou serviço, que reflete o cumprimento ou não por parte de quem forneceu o produto ou serviço. Mesmo quando se trata de uma repetição do consumo, a satisfação é um conceito que consiste numa avaliação pós consumo e temporária. A lealdade, pelo contrário, refere-se à preferência do consumidor pelo produto ou serviço e é mais durável. De acordo com este autor, a satisfação é uma primeira base para que haja lealdade do consumidor, embora não seja o seu elemento central. Enquanto os consumidores leais são normalmente consumidores satisfeitos, consumidores satisfeitos não se traduzem necessariamente em leais.

Bigné et al. (2001) estudaram a relação entre imagem (centrada nos atributos do produto e não na marca), qualidade, satisfação e lealdade. Estes autores comprovaram que a imagem é um fator chave no marketing de destinos turísticos, influenciando a escolha do destino, sendo um antecedente da qualidade, da satisfação e da lealdade. Provaram também que a qualidade tem uma influência positiva na satisfação e na intenção de voltar. No entanto, não ficou bem provada a relação da satisfação com a intenção de voltar a visitar o destino. Estes autores não consideraram no seu estudo as associações da marca, e a escala de satisfação teve apenas um único item, o que sugere mais investigação, como os próprios autores referiram.

Formulam-se, assim, as seguintes hipóteses:

$H^{3 a}$ : Existe um impacto significativo da satisfação na atitude de lealdade em relação à marca do destino turístico.

$\mathrm{H}^{3 \mathrm{~b}}$ : A satisfação medeia a relação entre a imagem da marca e a atitude de lealdade em relação à marca do destino turístico. 


\section{Modelo conceptual}

A maioria dos estudos sobre IDT inclui a dimensão da qualidade (Pike, 2002), mas a maioria dos estudos recentes que estudam a imagem numa abordagem de branding não integram esta dimensão que é considerada fundamental (Aaker, 1991) para perceber o valor da marca. Konecnik e Gartner (2007) estudaram a relação entre o reconhecimento da marca, imagem, qualidade e a lealdade mas não incluíram a dimensão da satisfação, e sugeriram mais dimensões no estudo da imagem/associações da marca. O modelo conceptual de destination branding de Qu et al. (2011) estudaram as componentes da imagem (cognitiva, afetiva e única, esta última introduzida por estes autores) relacionando-as com a imagem global, sendo a imagem mediadora entre as associações da marca e o comportamento futuro dos turistas. No entanto, as associações da marca centraram-se nos atributos do produto incluindo nelas a avaliação da qualidade da experiência. Estes autores concluíram que mais associações da marca devem ser incluídas nos estudos.

Não foi identificado na revisão da literatura estudos publicados com todos os constructos considerados no presente estudo, que integra várias associações da marca, bem como os constructos da qualidade percebida e da satisfação e a lealdade. O presente modelo poderá, assim, ser a contribuição para o desenvolvimento conceptual do destination branding. A revisão de literatura sugeriu a colocação das hipóteses fundamentadas na secção anterior (2). As hipóteses permitirão, por um lado testar a validade e relevância científica do modelo conceptual, e por outro lado contribuir para uma maior conhecimento sobre a imagem da marca do destino turístico em que o modelo será testado, o Porto e Norte de Portugal.

Conforme se pode verificar na figura 1, o modelo conceptual proposto inclui 5 dimensões de associações da identidade da marca que antecedem e formam o constructo da imagem da marca. A imagem da marca estabelece, por sua vez, relação com os outros constructos que a revisão de literatura sugeriu. Isto é, o modelo foi formado com o que se revelou oportuno incluir para estudar, visando contribuir para o desenvolvimento conceptual do destination branding.

Figura 1. Modelo Conceptual

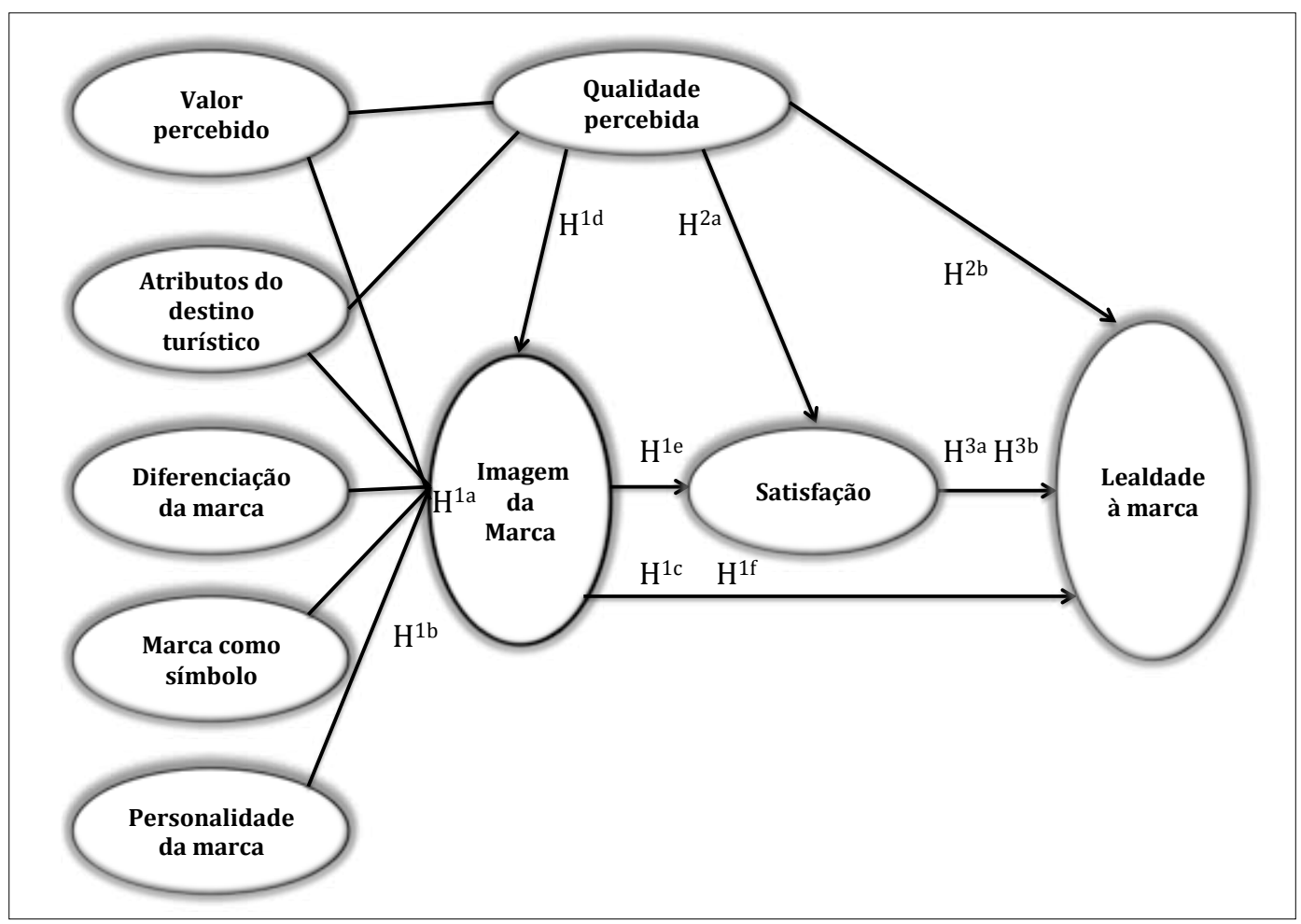




\section{Metodologia}

Optou-se pelo método de comunicação direta, através de inquérito, com questionário ordenado e estruturado. Esta pesquisa é quantitativa com medição por escalas (Likert de sete categorias ou pontos). Os sujeitos são turistas estrangeiros em situação de pós-consumo. O local de recolha direta de dados é a gare de embarque (partidas) do Aeroporto Francisco Sá Carneiro (AFSC) no Porto. Os sujeitos serão pré-qualificados antes de responderem ao questionário, excluindo-se os residentes em Portugal e os passageiros em trânsito. Na recolha direta de dados primários através de questionário seguiu-se uma amostra não-probabilística por conveniência. Como não estão disponíveis dados precisos sobre o tamanho da população, como é o caso no presente estudo, não é viável um procedimento de amostra probabilística (Prayag, 2009).

Procurou-se dar a maior consistência às escalas, construindo-as com base em adaptações de escalas cientificamente comprovadas, combinando na escala de cada constructo itens de mais do que uma escala e, em alguns casos, de mais do que um autor.

O questionário foi desenvolvido em função dos constructos a testar, das escalas e dos itens identificadas para os medir e com as questões necessárias para analisar o perfil do turista. A escala intervalar tipo Likert de 7 pontos foi usada para medir todos os constructos e relação entre eles. Assim, para medir as associações da marca/imagem da marca, a satisfação e a atitude de lealdade optou-se por uma escala intervalar desde 1 "discordo totalmente" a 7 "concordo totalmente". Para avaliar a qualidade percebida optou-se por uma escala de Likert de 7 pontos desde 1 "muito má" a 7 "muito boa". O questionário foi vocacionado para ser autoadministrado embora com assistência, desenvolvido com questões simples e instruções explícitas, e será disponibilizado nos idiomas: Alemão, Espanhol, Francês, Inglês, Italiano e Português. Será efetuado um pré-teste para verificar a consistência e a fiabilidade do instrumento de recolha de dados.

Para o tratamento estatístico descritivo será utilizado o software SPSS, e para o tratamento estatístico multivariado, com análise de equações estruturais (AEE), serão utilizados os softwares PLS-SEM e SPSS-AMOS, visando aferir a qualidade de ajustamento do modelo e testar as hipóteses formuladas, quer as colocadas para testar diretamente as dimensões propostas como antecedentes da imagem da marca (associações da marca), quer as formuladas para relacionar este constructo da imagem da marca com os constructos: qualidade percebida, satisfação e lealdade.

\section{Conclusões}

O conceito de IDT é complexo (Echtner e Ritchie, 1991) mas significativamente relevante para a escolha dos destinos turísticos (Buhalis, 2000). A abordagem do estudo da imagem centrada nos atributos dos destinos turísticos enquanto produtos sugere ser redutora (Pike, 2009), na medida em que o branding é determinante num contexto cada vez mais competitivo dos destinos (Morgan et al., 2002), o que exige uma avaliação contínua do comportamento do consumidor e da performance dos destinos turísticos. As implicações da revisão de literatura permitem concluir que a investigação no domínio do branding de destinos turísticos é recente e que carece de um maior desenvolvimento conceptual (Pike, 2002; Pike, 2009). Os avanços foram sentidos através de estudos centrados no valor da marca na perspetiva do consumidor, replicando modelos de estudo de outros setores (Aaker, 1991; Keller, 1993) no turismo (Konecknik e Gartner, 2007; Prayag, 2009), mas que não permitiram ainda o necessário avanço de conceptualização para o branding de destinos turísticos, sobretudo porque: (1) apesar de se reconhecer a importância das associações da identidade da marca (Aaker, 1991; Keller, 1993) para o branding, no caso dos destinos turísticos, as associações tem vindo a ser estudadas pelos autores de forma insuficiente, ou seja não testando várias associações em simultâneo no sentido de perceber quais são as que melhor explicam a perceção da imagem da marca; (2) a relação das associações/imagem da marca com outros constructos importantes como a qualidade percebida e satisfação, ou não são considerados nos estudos ou não são incluídos em simultâneo para estudar as relações; (3) a abordagem conceptual com base no conceito destination branding foi notoriamente ainda pouco explorada (Cai, 2002; Pike, 2009; Qu et al., 2011). Neste contexto, o presente estudo representa a proposta de um modelo de destination branding, que tendo como núcleo central a imagem da marca precedido das associações da marca (não demasiado centrada nos atributos do produto) não negligencie a relevância da qualidade percebida e da satisfação, nem a multidimensionalidade da lealdade, incluindo o relacionamento do cliente com a marca. 


\section{Bibliografia}

Aaker, David.

1991. "Management brand equity". New York: The Free Press.

Aaker, David.

1996. "Building Strong Brands". New York: Free Press.

Aaker, D. e Joachimsthaler, E.

2007. "Liderança de marca". Lisboa: Planeta DeAgostini, SA.

Aaker, Jennifer.

1997. "Dimensions of brand personality". Journal of Marketing Research. 34(3): 347-356.

American Marketing Association Dictionary.

2014. "Brand and brand image definitions". Disponível em: https://www.ama.org/resources/Pages/

Dictionary.aspx?dLetter=B\&dLetter=B [consultado em 10/06/2014].

Anholt, Simon.

2003. "Branding places and nations. In R. Clifton and J. Simmons R. Brands and Branding, pp. 213-226,

London: The Economist Newspaper Ltd.

Bandyopadhyay, S., \& Martell, M.

2007. "Does attitudinal loyalty influence behavioural loyalty? A theoretical and empirical study". Journal of Retailing and Consumer Services. 14(1): 35-44.

Bigné, J., Sanchez, M. I., \& Sanchez, J.

2001. "Tourism image, evaluation variables and after purchase behaviour: Interrelationship". Tourism

Management. 22(6): 607-616.

Blain, C., Levy, S., \& Ritchie, B.

2005. "Destination branding: Insights and practices from destination management organizations". Journal of Travel Research. 43: 328-338.

Buhalis, Dimitrios.

2000. "Marketing the competitive destination of the future". Tourism management. 21(1): 97-116.

Cai, Liping.

2002. "Cooperative branding for rural destinations". Annals of Tourism Research. 29(3): 720-742.

Echtner, C., \& Ritchie, J.

1991. "The meaning and measurement of destination image". Journal of Tourism Studies. 2(2): 2-12.

Ekinci, Y., \& Hosany, S.

2006. "Destination personality: An application of brand personality to tourism destinations". Journal of Travel Research. 45(2): 127-139.

Gartner, William.

1993. "Image formation process". Journal of Travel and Tourism Marketing, 2(3): 191-212.

Grönroos, Christian.

2004. "Marketing: gerenciamento e serviços". Rio de Janeiro: Elsevier.

Hudson, S. e Ritchie, B.

2009. "Branding a memorable destination experience. The case of Brand Canada. International Journal of Tourism Research. 11(2): 217-228.

Keller, Kevin.

1993. "Conceptualizing, measuring, and managing customer-based brand equity". Journal of Marketing. 57(1): 1-22.

Keller, Kevin.

2003. "Strategic brand management: Building, measuring, and managing brand equity". Upper Saddle River, N.J: Prentice Hall.

Konecknik, M., \& Gartner, W.

2007. "Customer-based brand equity for a destination". Annals of Tourism Research. 34(2) 400-421.

Martín, H., e Bosque, I.

2008. "Exploring the cognitive-affective nature of destination image and the role of psychological factors in its formation". Tourism Management. 29(2): 263-277.

Morgan, N., Pritchard, A., e Pride, R.

2002. Destination Branding: Creating the Unique Destination Proposition. Oxford, UK: Butterworth-Heinemann. 
Nam, J., Ekinci, Y., e Whyatt, J.

2011. "Brand Equity, Brand Loyalty and Consumer Satisfaction". Annals of Tourism Research. 38(3): 1009-1030.

Oliver, Richard.

1980. "A cognitive model for the antecedents and consequences of satisfaction decisions". Journal of Marketing Research. 17(4): 460-469.

Oliver, Richard.

1999. “Whence consumer loyalty?". Journal of Marketing, 63 (Special issue 1999): 33-44.

Pike, Steven.

2002. "Destination image analysis - A review of 142 papers from 1973 to 2000". Tourism Management. 23(5): 541-549.

Pike, Steven.

2009. "Destination brand positions of a competitive set of near-home destinations. Tourism Management. 30(6): 857-866.

Prayag, Girish.

2009. 'Tourists' evaluations of destination image, satisfaction, and future behavioral intentions: The case of Mauritius". Journal of Travel \& Tourism Marketing. 26(8): 836-853.

$\mathrm{Qu}, \mathrm{H} ., \mathrm{Kim}, \mathrm{L} .$, \& Im, H.

2011. "A model of destination branding: Integrating the concepts of the branding and destination image". Tourism Management. 32(3): 465-476.

Ramos, P., Salazar, A., Gomes, J.

2000. "Trends in Portuguese tourism: a content analysis of association and trade representative perspectives". International Journal of Contemporary Hospitality Management. 12(7): 409-416.

Yoo, B. e Donthu, N.

2001. "Developing and Validating a Multidimensional: Consumer-Based Brand Equity Scale". Journal of Business Research. 52(1): 1-14.

Zabkar, V., Brenc, M., e Dmitrovic, T.

2010. "Modelling perceived quality, visitor satisfaction and behavioural intentions at the destination level”. Tourism management. 31(4): 537-546. 